\title{
Artelogie
}

Recherche sur les arts, le patrimoine et la littérature de l'Amérique latine

$11 \mid 2017$

Délocalités, translocalités et activisme dans l'art électronique et biomédiale latino-américain

\section{Arte em vórtice}

\section{Lucia Santaella}

\section{(2) OpenEdition}

Journals

\section{Edição electrónica}

URL: http://journals.openedition.org/artelogie/1455

DOI: 10.4000/artelogie. 1455

ISSN: 2115-6395

\section{Editora}

Association ESCAL

Refêrencia eletrónica

Lucia Santaella, «Arte em vórtice », Artelogie [Online], 11 | 2017, posto online no dia 01 dezembro 2017, consultado o 21 abril 2019. URL : http://journals.openedition.org/artelogie/1455 ; DOI : 10.4000/artelogie.1455

Este documento foi criado de forma automática no dia 21 Abril 2019.

Association ESCAL 


\section{Arte em vórtice}

\section{Lucia Santaella}

1 Os dicionários nos dizem que um vórtex ou vórtice é um escoamento giratório no qual as linhas de corrente apresentam um padrão circular ou espiral. São movimentos espirais ao redor de um centro de rotação que resulta da diferença de pressão de duas regiões vizinhas. A vorticidade é gerada porque o fluido tende a equilibrar o sistema e flui para o centro de rotação, mudando, eventualmente, a direção original do escoamento. Vórtices são encontrados nos mais diversos locais da natureza, como correntes circulares de água vindas de marés conflitantes, uma ilha no meio do oceano, furacões, tornados. Os sinônimos são: redemoinho, sorvedouro, torvelinho, turbilhão, furacão, voragem.

O sentido da palavra é também tomado metaforicamente para qualificar estados extremos de energia vital, em que esta gira mais velozmente até atingir o seu limite físico. A palavra pode ainda ser transposta para um redemoinho de emoções, quando estas chegam ao máximo de sua escala. Na psicanálise lacaniana, esses estados físicos ou psíquicos extremos são definidos como gozo, ou seja, o engodo que nos leva a crer que o prazer, a satisfação, o desejo, a felicidade podem existir em estado absoluto, que a plenitude é alcançável. A imagem magna desse desejo inatingível de completude estaria no prazer absoluto. Assim, vórtices físicos ou psíquicos seriam imersões no gozo sem o entrave de nenhum limite, estados do impossível, imagens excessivas e absolutas que se limitam com a morte.

3 A explanação acima aí comparece para introduzir um complexo projeto de arte, arquitetura e intervenção urbana que, desde 2013, sob a tutela de Nelson Brissac, não por acaso, se denomina ZL Vórtice, pois, no seu escopo de interferência ou militância em zonas urbanas em condições extremas, não apenas se coloca frente a frente com a voragem dos abismos sociais quanto também, ao assim fazê-lo, no seu modo radical de engajamento, acaba por tangenciar, ou melhor, colocar em rotação, por proximidade e distanciamento, uma série de tendências estéticas e práticas artísticas tais como artes locativas, partilhas do sensível, site specific, design de ativismo (activism design), artivismo, entre outras. 0 objetivo deste artigo é apresentar e discutir o projeto ZL Vórtice, para, então, evidenciar seus tangenciamentos assintóticos nessas várias direções estéticas contemporâneas. 


\section{As quatro edições de Arte/Cidade}

4 As raízes do projeto ZL Vórtice encontram-se em 1994, quando se iniciou o primeiro dos quatro grandes projetos de Arte/Cidade, curados por Nelson Brissac. Trata-se de megaeventos (Arte/Cidade I, 1994; Arte/Cidade II, 1994; e megaintervenções Arte/Cidade III, 1997 e Arte/Cidade IV, 2002), pensados para os desafios cruciais apresentados pelas metamorfoses contínuas e contraditórias das megacidades, concebidas como sistemas dinâmicos fora do equilíbrio, no contexto da globalização.

5 A primeira edição, nomeada Cidade sem janelas, ocupou o antigo e desativado matadouro municipal localizado no bairro da Vila Mariana. O projeto, ousado pelas dimensões e originalidade, viabilizou-se graças à gestão de Ricardo Ohtake na Secretaria da Cultura do Estado. Para esse gestor, o Estado não deveria cumprir tão só e apenas a função de um aparato burocrático, mas deveria encorajar e abrigar ações culturais e artísticas experimentais que, pela novidade e risco que implicam, não são facilmente abraçadas pelo mercado corporativo.

6 Tirando proveito dessa abertura, a proposta de Brissac visava promulgar a interação de artistas de diversas áreas - música, arquitetura, vídeo, artes plásticas, fotografia lançando-lhes o desafio de ocupação transformadora e fiel à estranheza simbólica do espaço e de sua memória. A iniciativa deixava clara a busca de ruptura, de um lado, com o isolacionismo do artista, de outro, com os espaços convencionais de exposição da arte, gastos pela tradição. Estava implícita no desafio a expectativa de que a capacidade criadora do(a)s artistas o(a)s habilitasse a trazer de volta à vida, transmutado, um espaço público degradado.

7 Ainda no mesmo ano, sob o nome de A cidade e seus fluxos, a segunda edição do projeto deslocou as intervenções para o centro nevrálgico da cidade de São Paulo, o Vale do Anhangabaú como cenário das intervenções artísticas. Foram ocupados três edifícios: o último andar do prédio da Eletropaulo, hoje destinado ao Shopping Light, os três andares do edifício do Banco do Brasil que atualmente sedia o Centro Cultural BB e um andar do edifício Guanabara, ainda utilizado como lugar de comércio. Nessa edição, o projeto ganhou em ousadia, pois interferia nos usos habituais de sítios específicos do ambiente urbano, nesse caso, no âmago pulsante do gigantismo da cidade.

O tema dos fluxos, inspirado no frenesi do ambiente, colocava no front de atuação a imprevisibilidade da atenção nômade e fragmentada do transeunte, muito distinto do típico espectador de mostras artísticas intramuros. A escolha do local orientou-se não só por sua agitação em ritmo convulsivo, mas, sobretudo, pelas condições inauditas do Vale do Anhangabaú. Nas palavras de Brissac,

Uma via expressa construída sobre o rio, recoberta por um jardim. $\mathrm{O}$ vale, os viadutos e os grandes edifícios vão acrescentando outras camadas a este verdadeiro palimpsesto urbano. O movimento contínuo, horizontal e vertical, dinamiza toda a área. As sucessivas mudanças na paisagem vão criando esta falha geológica, esta grande rasura. Extraordinária complexidade urbano-arquitetônica num recorte da cidade. (SECSO, 1994-2, s/p, apud Giudici, p. 18)

9 A terceira edição, Cidades e suas histórias, ambientou-se em uma parte das linhas de trem metropolitano já desativadas e em construções históricas no entorno da Estação da Luz e do Moinho e Indústrias Matarazzo. O conjunto é aí composto por uma estação de trens, A Estação da Luz, símbolo remanescente da opulência de uma era opulenta que feneceu, um 
trecho das linhas ferroviárias que, embora desativadas, trazem rastros da memória de locais do período de produção fabril de São Paulo: os silos do antigo Moinho Central, na Barra Funda, e os galpões e chaminés das Indústrias Matarazzo que se elevam ainda imponentes na paisagem do Bairro da Água Branca.

Conforme foi bem lembrado por Gama (2002, p. 279), devido ao aumento na escala de intervenção dentro da cidade, essa terceira edição colocou-se frente a frente com "questões vitais para o urbanismo, o transporte público, a topografia, o planejamento, a comunicação visual em terreno urbano e a arquitetura".

11 Ao público, a proposta era a de embarcar em um trem, especialmente reservado para o evento, com paradas pelos vários sítios selecionados para assistir a eventos e percorrer exposições. A viagem era mais de estranhamento do que de visitação, pois "o projeto optou por não vestir ou domesticar o local, não deixar palatável ao bom passeio uma ruína carregada de escombros" (ibid.). Os artistas, por sua vez, longe de suas zonas costumeiras de atuação, entregaram-se à tarefa de criar situações estéticas que brotavam dos locais como forças remanescentes das camadas submersas da memória urbana.

Então, a quarta e última edição, ArteCidade Zona Leste, intensificando o seu caráter experimental e radicalizando a sua natureza de "laboratório urbano" (Gama, ibid., p. 278) avançou por diversas áreas da zona leste da cidade de São Paulo. Para estabelecer as relações, potencializadas pelas intervenções, entre arte, arquitetura e urbanismo, depois de dois anos de pesquisa coletiva, o levantamento do local "obedeceu a certos critérios básicos: situações que apresentassem configurações complexas e reorganizadas pela implantação de vias de transporte, a realocação de atividades produtivas e serviços, a desativação de equipamentos industriais e a ocupação informal” (Brissac, 2011, p. 90). A partir disso, foi escolhido o Pátio do Pari, Avenida Rangel Pestana, Avenida Salim Farah Maluf, Estação Brás, Largo da Concórdia, Largo do Glicério, Radial Leste e Parque Dom Pedro. A seleção foi guiada pelo desinvestimento sofrido pela região outrora pujante.

Na década de 1920, a zona Leste de São Paulo foi palco da industrialização nascente. Esta ocupava grandes construções de fábricas que se instalavam a todo vapor pelos bairros de Belém, Mooca, Pari e Brás e que traziam consigo moradias populares e comércio para o consumo emergente. Dos anos 1950 em diante, a região começou a passar por um processo de estagnação devido ao deslocamento das fábricas para outras regiões, deixando atrás de si paisagens melancólicas, marcadas por resíduos de uma potência que adormeceu e da qual restaram algumas zonas desertificadas, em estado de abandono, outras informalmente ocupadas entre corredores de passagem. Certo está Mammi (2002, p. 280), quando afirma que "São Paulo não nasceu de um conjunto de moradias, mas de uma empreitada industrial, que já embutia em si toda violência posterior".

A parceria com o SESC, iniciada desde a edição 3, aprofundou-se nessa nova edição. Para o SESC, a sua incorporação no projeto visava valorizar a memória da história social e produtiva da área urbana em que estava inserido seu programa cultural, suportado por uma esplêndida realização arquitetônica. Esses propósitos o Arte/Cidade vestia como uma luva com o horizonte que abria para a utilização do edifício como local de combinações estéticas múltiplas, abertas a experimentos inovadores, implantados paradoxalmente nas instabilidades dinâmicas da cidade.

15 Aos artistas foi sugerida a identificação e interferência nos ritmos dinâmicos em desequilíbrio tanto urbanos quanto sociais da área cartografada. Assim, a partir do foco de irradiação localizado no Sesc Belenzinho, as intervenções artísticas espraiaram-se, à 
escolha dos artistas, pelas áreas em estado de tensão, entre a inércia e a iminência transformativa que caracterizava a região ${ }^{1}$. Nas palavras de Brissac $(2011$, p. 15), os artistas e arquitetos

[...] desenvolveram propostas de intervenção para diferentes situações de região. Projetos que indicam procedimentos alternativos diante da reestruturação global da cidade, baseados na ativação dos espaços intersticiais e na diversificação do uso da infraestrutura. Propostas que, em certa medida, retomam os procedimentos engendrados pelas populações itinerantes que ocupam esses vazios urbanos. São operações que visam detectar o surgimento de novas condições urbanas, identificar suas linhas de força e instrumentalizar seus agentes. Intervenções que se contrapõem à apropriação institucional e corporativa do espaço urbano e da arte.

16 A quarta edição do Arte/Cidade gerou, logo a seguir, uma nova modalidade de intervenção urbana regida pela cartografia de toda uma área da Zona Leste englobando "os elementos urbanos, arquitetônicos e sociais existentes, os sistemas de transporte e comunicação ali implantados e, sobretudo, as operações e projetos urbanos, arquitetônicos e artísticos previstos ou em andamento na região" (Brissac, s/d). Trata-se de uma cartografia líquida, beirando o impossível, devido à descontinuidade e variabilidade de uma estrutura urbana e social cujo tecido apresenta profundas rupturas, "seguidas de ocupações improvisadas e auto organizadas das áreas remanescentes, gerando um território difuso, desprovido de delimitações precisas entre os diferentes recortes e uso do espaço. Uma zona indefinida e movente." (Brissac, 2011, p. 79)

17 Como articular espaços fragmentados, descontínuos, intervalares? Em vez de buscar forjadas unidades, o curador foi ao encontro de analogias concretas entre zonas urbanas similares, ambas descosidas por interrupções e vazios: o Brás (em São Paulo) e o Mitte (em Berlim), bairros que, no momento, funcionavam similarmente como cicatrizes abruptas, hiatos desordenados tomados como pontos de partida para reflexões e intervenções. Estas, muito mais regionais do que locais, tinham em mira, por meio de atuações tensionadoras e articuladoras, reorientar tendências, redirecionar fluxos e dinâmicas urbanas. Para isso, foi realizado

[...] um levantamento dos planos diretores, do tipo de ocupação (estrutura urbana, tipologia arquitetônica, usos e características sociais e históricas), dos circuitos existentes ou planejados de transporte e circulação, dos diversos projetos de revitalização e das diversas operações urbanas propostas ou em andamento. Acrescentando avaliações críticas, projetos de caráter urbano-arquitetônico já concebidos para a área, projetos especialmente formulados, intervenções nos circuitos de transporte e comunicações, intervenções (efêmeras ou permanentes) urbanas, arquitetônicas e artísticas. (Brissac, s/d)

18 A composição dos mapas realizou-se em vários planos (ocupação, viário) e os projetos obedeciam a diferentes escalas e natureza (público/individual, existente/projetado, viabilizado/especulativo) para gerar diferentes tipos de trânsito entre as situações, operações e projetos, para trabalhar as relações (espaciais, funcionais, sociais, estéticas) entre eles e "explorar as múltiplas combinações possíveis, produzindo contínuas composições cartográficas" (ibid.). Dessa complexa rede participaram prestigiosos nomes nacionais e internacionais da arte e do pensamento contemporâneo, com bagagem reconhecida em projetos situacionais e transculturais. ${ }^{2}$ 


\section{Diferenças que fazem a diferença}

19 As edições de Arte/Cidade não podem ser confundidas com eventos de arte nas ruas, arte pública ou similares. Para começar, não se trata de intervenções pontuais, inscritas em lugares precisos, pois, intervenções "hoje só ganham significado em relação à situação urbana mais ampla” (Brissac, 2002, p. 27). Entretanto, na sua escala a cada edição mais expandida, Arte/Cidade ainda menos se confunde com projetos que convertem as cidades em campo de uma nova monumentalidade e que as remetem a relações com a indústria cultural, o turismo e o entertainment, ou seja, "estratégias de revitalização urbana através da utilização do patrimônio histórico como sítio de exibição da arte e espetáculos". As intervenções públicas monumentais, que transformam as cidades contemporâneas em cidades-museus, incitam ao voyeyrismo e à percepção à distância desses lugares". (ibid). Em larga escala, mas em flagrante oposição ao monumentalismo exibicionista, caminhando pelo fio de uma navalha, Arte/Cidade buscou penetrar no âmago das ambivalências e instabilidades da cidade traduzidas esteticamente pelas artes no seu poder de ressignificação dos espaços urbanos feridos pela marginalização excludente.

20 A proposta, portanto, foi sempre a de explorar as cicatrizes e ruínas dos "não-espaços", expressão aqui tomada em um sentido próximo, mas distinto daquele dado por Marc Augé (1994, p. 73-77), segundo o qual, em oposição aos lugares antropológicos que são identitários, relacionais, históricos e criam um social orgânico, os não-lugares da supermodernidade criam tensão solitária. Para ele, esses são os espaços de circulação nos quais não há lugar para o pouso compartilhado, mas apenas para o anonimato da solidão nos circuitos da massa humana.

21 Igualmente, as cicatrizes urbanas que Brissac explora para a transmutação criativa e interferente, embora muito próximas, também não se confundem inteiramente com os espaços vazios de Bauman (2011, p. 112-114), ou seja, espaços esvaziados de significado porque negligenciados pelos urbanistas e ausentes dos mapas mentais que orientam o olhar do cidadão na sua vivência urbana. Não se confundem ainda com as ruínas de que fala Augé (2010, p. 67-70), ou seja, monumentos históricos corroídos pelo tempo que se transformam em espetáculo para o turismo de massa. Tais distinções são fundamentais para que se possa entender com mais justeza o desígnio transformador que norteia os projetos desenvolvidos por Brissac.

"Quando as recentes políticas urbanas de revitalização e as formas estabelecidas de arte pública entram em colapso diante da complexidade e escala das novas situações, Arte/ Cidade se propõe a discutir novas estratégias urbanas e artísticas de intervenção em megacidades". As intervenções devem ser capazes de "transcender sua locação imediata e remeter ao vasto território da megacidade e das reconfigurações globais da economia, do poder e da arte" de modo a provocar a percepção "para situações que não se revelam mais apenas à exploração in loco, ao escrutínio visual. O que deve ser levado em conta são "os processos de reestruturação metropolitana e global, mas que se contraponham à apropriação institucional e corporativa dos espaços urbanos e das práticas artísticas." (Brissac, 2006, p. 86)

23 Para isso, foram estabelecidos procedimentos e estratégias relativos à escolha das situações e às táticas artístico-urbanísticas a serem empregadas, envolvendo, inclusive, interações com políticas públicas ligadas à arte e ao uso do espaço da cidade. Os questionamentos levantados por Brissac (ibid.) são esclarecedores: 
Diante da nova relação entre arte e desenvolvimento urbano, quais são as alternativas que se abrem para projetos de intervenção nas metrópoles em processo de reestruturação global? Eles podem voltar-se para as vastas áreas, extraordinariamente complexas e dinâmicas, informes, excluídas dos projetos de desenvolvimento urbano. Podem apontar para alternativas à ocupação, por megaprojetos de desenvolvimento imobiliário, adensadores e estruturantes, de áreas hoje desinvestidas. Indicando, diversamente, programas que correspondam à indeterminação dinâmica desses territórios intersticiais. Propostas de configurações e usos de infra-estrutura que intensifiquem e diversifiquem as articulações na trama metropolitana. Intervenções programáticas potencializadoras de situações urbanas, em relação direta com as comunidades. Distintas de obras ditadas pelo desenho existente da cidade e pelos interesses econômicos e sociais dominantes. Uma possibilidade de introduzir novas estratégias urbanas.

Tudo isso, de um lado, no confronto com o surgimento de grandes projetos urbanoarquitetônicos financiados pelo capital internacional que tende a configurar enclaves autossuficientes e isolacionistas, enquanto abandonam o restante do tecido urbano "à decadência, à exclusão e à violência". De outro lado, em oposição às perspectivas "dos megamuseus e exposições temáticas de itinerância internacional", que submetem "a produção e a percepção estéticas à mesma lógica espacial global, com seus imensos ambientes artificiais e cenografados. Uma monumentalidade que disponibiliza a cidade e a arte ao espetáculo e ao turismo cultural". (ibid., p. 87)

O confronto e a oposição não se caracterizam pelo conforto da troca do monumental pela modéstia do apequenamento, mas pelo enfrentamento da grande escala e da hipercomplexidade espacial, institucional e social das situações urbanas em contínua dinâmica de reestruturação. Disso decorrem estratégias antagônicas “à circunscrição espacial, à forma arquitetônica totalizante e à instrumentalização institucional ou corporativa da arte" (ibid.). Trata-se de um radical descolamento da percepção urbana de tudo aquilo que guia os padrões urbanísticos voltados para a monumentalidade regida pela lógica do marketing, da promoção imobiliária e do turismo cultural de que muitos espetáculos de arte para espaços públicos estão em sintonia.

Em suma: Arte/Cidade colocou em ativação espaços intersticiais, que, na reviravolta dos seus vestígios, traziam à tona ressignificações da história e sinalizações de futuro, tendo em mira intervir na dinamicidade urbanística e social.

A observação dos passos que foram dados de uma edição de Arte/Cidade para a seguinte, o que fica muito nítido é a intensificação do radicalismo de seus propósitos, cada vez penetrando mais fundo e aumentando a escala do debate e da interferência na hipercomplexa dinâmica dos espaços urbanos, no fogo cruzado das corporações e das ações governamentais. Já em 2006 (p. 88-89) Brissac se perguntava: Será que

Arte/Cidade - originalmente um projeto de intervenções artísticas no espaço urbano - poderia evoluir para converter-se num campo de discussão sobre os processos de reestruturação urbana, onde intervenções artísticas e urbanísticas ganhem outra escala e significado? Será capaz de obter suficiente credibilidade para poder discutir iniciativas governamentais e de grandes corporações privadas? É possível, no cenário vigente da administração das cidades e da cultura, dominado por operações corporativas e institucionais de grande poder econômico e político, criar um espaço público de debate sobre as alternativas de desenvolvimento urbano e de produção artística?

8 Nessas perguntas estava sendo gestado o projeto ZL Vórtice na sua busca pela geração de modelos de participação, de negociação e de novos instrumentos para a condução de projetos e processos urbanos, voltados para a recuperação de espaços civis degradados. 
Muito longe da mera e muitas vezes sensacionalista estetização da ruína, da marginalização, da negligência, do abandono e da vulnerabilidade da miséria, os projetos que partiram de Arte/Cidade para Vórtice são, acima de tudo, disruptivos, proativos e estéticos, no sentido grego de Kalos, o admirável.

\section{O projeto ZL Vórtice}

da nossa sociedade: a) nas secas que afetam a região Nordeste e causam a migração e a ocupação das áreas disponíveis (junto aos rios) na cidade de São Paulo; b) na incapacidade dos programas habitacionais de dar conta da grande demanda por moradia e, finalmente, c) na falta de políticas adequadas de preservação ambiental e de recursos hídricos. Os efeitos são a locação de grandes populações em situações insalubres, a destruição dos sistemas fluviais e da paisagem natural e o grande comprometimento dos recursos hídricos.

As intervenções na região Leste de São Paulo trouxeram para Brissac a aquisição de conhecimento e o aguçamento da sensibilidade para os cruciais dilemas dessa área da cidade. $O$ aprofundamento e a radicalização crescentes já perceptíveis na sequência das edições de Arte/Cidade o levaram para a detecção de uma situação urbana em condição extrema da qual emergiu o projeto ZL Vórtice. Este vem sendo desenvolvido desde 2013, em um perímetro urbano de grandes dimensões, que abrange os bairros de União de Vila Nova, Jardim Lapenna, Jardim Helena (Pantanal) e Vila Itaim, situados na área de várzea do Rio Tietê, na extremidade leste do município de São Paulo, nos trechos onde ainda estão preservados os últimos meandros do rio.

area às margens do rio foi ocupada, formando bairros intensamente povoados (300 mil pessoas habitam esses espaços). Desde então, o assoreamento dos canais, o aumento da instabilidade climática e a ocorrência repetida de grandes inundações levou as condições urbanas e ambientais na área a um estado de degradação. A várzea apresenta-se, assim, como uma situação limite. Limite de tensões, de precariedade habitacional, de contradições, de conflitos, de instabilidades. A busca de intervenção crítico-criativa de Brissac, trazendo inovação para uma situação desse caráter é, antes de tudo, o ato de uma infatigável coragem que não conhece repouso. áreas, de um lado, sofrem o impacto de grandes obras de infraestrutura metropolitana (especialmente de contenção de enchentes), de outro, são pressionadas pela regulamentação de proteção ao meio ambiente. Forma-se aí um cadinho de relações contraditórias, um fogo cruzado em que se confrontam os interesses da administração pública, de organizações civis e de associações comunitárias.

A categorização dos problemas assim se apresenta: a) ocupações rudimentares, desprovidas de infraestrutura (esgoto e fornecimento de água e eletricidade) e serviços sociais; b) a necessidade de novas soluções de infraestrutura e manejo de águas, condizentes com a escala das áreas ocupadas e o desequilíbrio socioambiental, agravado pelas enchentes; c) a dificuldade de estabelecer políticas públicas convergentes para ocupações em áreas de preservação ambiental, para permitir serviços públicos.

As causas desses problemas podem ser identificadas na histórica desigualdade econômica 

grandes investimentos em infraestrutura e equipamentos públicos, o que a caracteriza como um lugar de emergência de novas configurações urbanas e de novas práticas sociais. O complexo de órgãos e organizações envolvidos na região são os seguintes: a) órgãos da administração pública, como o Departamento de Águas e Esgoto (DAEE), a Secretaria de Estado do Meio Ambiente (SMA), a Companhia de Desenvolvimento Habitacional e Urbano (CDHU) e a Secretaria Municipal do Desenvolvimento Urbano (SMDU), que têm projetos para a região; b) organizações sociais sem fins lucrativos, como a Fundação Tide Setubal e o Instituto Alana, e c) as associações de moradores: Viveiro Escola (União de Vila Nova), Nova União das Artes (NUA), Sociedade Amigos do Jardim Lapenna, Associação dos Moradores do Jardim Pantanal (AMOJAP) e Acaleo Ação Cultural (Vila Itaim).

experiência adquirida nos projetos de Arte/Cidade, Brissac enxergou nas ambivalências dessa dinâmica urbana, ambiental e social, a possibilidade de iniciativas com vistas a promover sistemas inovadores de drenagem urbana e manejo de águas em áreas críticas, com participação e capacitação técnica dos moradores. Situações emergenciais apresentam o potencial para alavancar transformações nas práticas e políticas públicas, favorecendo uma maior articulação entre os agentes públicos, universidades, organizações sociais, artistas participativos e moradores.

Visa-se, portanto, contribuir para a orientação de políticas públicas baseadas na convergência de agentes e ações. Alimentado por esses ideais, ZL Vórtice vem se desenvolvendo como um canteiro de experimentação de novos procedimentos e técnicas para condições extremas. Portanto, um projeto de investigação e práticas urbanas e ambientais experimentais com o objetivo de formular alternativas estratégicas e desenvolver protótipos de dispositivos concretos que contribuam para recuperar o meio ambiente e revalorizar os recursos hídricos. uso de sistemas naturais como infraestrutura, integrados aos ciclos de vazão do rio; b) dispositivos de manejo de águas e drenagem sustentável; c) infraestrutura integrada de esgoto e fornecimento de água e eletricidade; d) novas tecnologias de sistemas de drenagem, fabricados localmente pelas comunidades; e) design e produção de espaços públicos e capacitação dos moradores para monitorar e preservar o meio ambiente. Isso envolve, por sua vez, pesquisar e testar materiais e procedimentos construtivos em terrenos à beira de rios e córregos; dispositivos sustentáveis de drenagem; métodos de fabricação digital de moldes e composições de concreto e pigmentos adequadas para a fabricação local em larga escala na várzea.

d) a realização de um levantamento geomorfológico e urbano-ambiental da área, com um diagnóstico do território, incluindo aspectos das dinâmicas socioeconômicas e os projetos públicos existentes. 

propostas e políticas públicas consistentes, ZL Vórtice visa apresentar projetos efetivamente construídos. Projetos-piloto de um sistema de drenagem sustentável, de um dispositivo local de calçadas drenantes, de espaço público (piso intertravado permeável) desenhado pelos moradores e de mobiliário urbano feito com módulos de adobe. Também serão elaborados, com as comunidades, os sistemas informacionais de monitoramento do rio e de depósitos de lixo. prioritário de ZL Vórtice. O desenvolvimento dos projetos, nos laboratórios da USP e da PUC-SP, está sendo feito com a participação ativa de um grupo de moradores, escolhidos para depois disseminarem o conhecimento técnico adquirido e orientarem atividades realizadas na região. Toda a tecnologia desenvolvida nos laboratórios (materiais e sistemas construtivos) é concebida para ser compreendida e manipulada pelos moradores, em função de suas condições locais. projeto nunca deixou de considerar os impactos que pode sofrer pelo efeito de diversas variáveis, causando atrasos nos trabalhos: 
56 a) a ocorrência de instabilidades climáticas catastróficas, inundações muito mais intensas do que as correntes, desorganizando o precário tecido social; críticas, portanto grande parte das periferias das cidades brasileiras. Sobretudo as áreas de mananciais e bacias hidrográficas fortemente afetadas por ocupações desorganizadas e poluição. A planejada publicação de manuais de operação visa exatamente assegurar a utilização desses princípios por outros agentes, em outros locais. ${ }^{3}$

\section{Tangenciar entre a atração e a retração}

65 Na apresentação, acima realizada, da trajetória que vai de 1994 até os dias de hoje (setembro/2017), cobrindo as quatro edições de Arte/Cidade e seu prolongamento em Brasmitte e, desde 2013, em ZL Vórtice, por opção consciente e deliberada, deixei de colocar ênfase nas obras muitas vezes magníficas de artistas que participaram de todas essas edições. Essa deliberação se deu, em primeiro lugar, pela existência de dois volumes esplendorosos (Brissac, org., 2002 e Brissac, 2011) povoados de imagens com impressionante qualidade, apresentações dos artistas, descrições das obras e leituras críticas. Tentar replicar esse esplendor com poucos exemplos no presente artigo, minimizaria o valor da qualidade dessas publicações. Em segundo lugar, e esta é a principal razão, propositalmente pretendi colocar ênfase quase absoluta na especificidade do trabalho desenvolvido por Brissac. Com isso, almejo desenvolver o argumento de que o papel de curador, desempenhado por Brissac na primeira edição de Arte/Cidade, foi gradativamente misturando a atividade de curador com aquela de artista, no legítimo sentido do termo, até que, da quarta edição até o atual projeto ZL Vórtice, pode-se afirmar, sem hesitações, que o trabalho de Brissac é, sobretudo, o trabalho de um artista. 
66 As justificativas para esse argumento, irei buscar nos tangenciamentos que suas atividades apresentam com tendências artísticas contemporâneas, em que o papel, que Brissac tem desempenhado, se aproxima do papel que artistas têm desempenhado em projetos relativamente similares e que serão sinalizados a seguir. Essa sinalização não tem a intenção de fixar as propostas de Brissac em categorias estanques. Aliás, há sempre em suas propostas um movimento de atração por similaridade com tendências artísticas vigentes, mas, ao mesmo tempo, um movimento de retração, ou seja, aproximações e distanciamentos que delineiam o trabalho de Brissac com um perfil muito próprio.

\section{A partilha do sensível}

67 Na leitura que efetuou sobre as duas primeiras edições de Arte/Cidade, Giudice (2014) utiliza como referencial de apreciação e análise o conceito de "partilha do sensível", de J. Rancière (2005). Para este, essa expressão explicita “o cerne da política e, portanto, uma certa estética política" (p. 11). Que estética é essa?

Não a teoria da arte em geral ou uma teoria da arte que remeteria a seus efeitos sobre a sensibilidade, mas um regime específico de identificação e pensamento das artes: um modo de articulação entre maneiras de fazer, formas de visibilidade dessas maneiras de fazer e modos de pensabilidade de suas relações, implicando uma determinada ideia da efetividade do pensamento. (ibid., p. 13)

68 A noção de política de Rancière (1996, p. 367) não é menos original. Ela inclui a crítica ao discurso dominante "que identifica a racionalidade política ao consenso e o consenso ao princípio mesmo da democracia". O consenso, em verdade, é a supressão da política. 0 dissenso, ao contrário, tem por objeto o que Rancière chama de "recorte do sensível, a distribuição dos espaços privados e públicos, dos assuntos de que neles se trata ou não, e dos atores que têm ou não motivos de estar aí para deles se ocupar". Não se trata, portanto, "de conflito de classes ou de partidos, a política é um conflito sobre a configuração do mundo sensível na qual podem aparecer atores e objetos desses conflitos". (ibid. p. 373)

69 A política é, portanto, um campo de tensão entre formas de ser da comunidade, cada uma dessas formas realizando uma proposta de partilha do sensível. É o recorte que define as formas do espaço em que o comando se exerce. Formas que estabelecem o que é visível e dizível pela divisão fixa das funções e papeis, gerando, portanto, o dissenso, cerne da política.

70 À estética, por sua vez, segundo Giudice (2014, p. 21), cabe encontrar "novas formas sensíveis, dar visibilidade a feitos nunca antes realizados, criar lugares, signos e imagens concretos de uma vida futura". A partir disso, Giudice (ibid., p. 22) conclui que "Arte/ Cidade operou sobre essa capacidade de criar e rearranjar novas configurações do mundo sensível, apropriou-se da matéria-prima depositada nos espaços, investigou formas de enxergá-la, captá-la e produziu novos significados que alteraram a percepção estética tanto das obras em si quanto dos locais ocupados".

71 Embora as duas primeiras edições de Arte/Cidade tenham, de fato, realizado essas transformações, elas foram, contudo, apenas os pontos de partida para uma partilha do sensível que o ZL Vórtice vem realizando mais plenamente. Considerando-se que a distribuição do sensível é uma lei que separa a comunidade em grupos, posições sociais e funções, ou seja, uma lei que separa incluídos e excluídos, pressupondo uma divisão estética entre o visível e o invisível, o audível e o inaudível, o dito e o não-dito, então, a 
essência do político consiste em interromper as separações, quer dizer, a distribuição do sensível, ao suplementá-la com a participação daqueles que não têm lugar nas coordenadas perceptivas da comunidade, modificando desse modo o próprio campo estético político da possibilidade. Isto porque o único sujeito possível da política é o demòs (democracia).

72 Assim sendo, aqueles que não têm nomes, que estão invisíveis e inaudíveis, só podem tomar parte na política via transformação das coordenadas estéticas da comunidade, quando o pressuposto fundamental da política "somos todos iguais" é implementado. Não é justamente isso que ZL Vórtice vem implementando, quando coloca pesquisadores, artistas, cientistas, professores e comunidades locais nas condições de igualdade que são próprias do diálogo transformador?

\section{Site specific}

73 Entre as aproximações mais comuns que os projetos de Arte/Cidade costumam suscitar, encontra-se sua identificação com a tendência artística sob o nome de site specific (sítio específico). Assim é chamado um modelo de produção artística que não mais se relaciona com produções regulares da arte realizada em estúdios ou laboratórios, ao transferir sua reflexão e execução para situações e locais específicos. As obras passam, assim, a levar mais em consideração o sítio, a inserção arquitetônica, a escala urbana, as situações e a complexidade de seus vínculos com o contexto e as informações que ele implica.

De fato, ao se opor ao isolacionismo da produção artística, extrapolando os espaços convencionais que são reservados para a difusão e circulação das obras de arte, a saber, museus, galerias e mesmo festivais; ao propor a multiplicidade de linguagens da arte, inclusive promulgando formas de intercâmbio entre artistas, Arte/Cidade, à primeira vista, pode ser enquadrada dentro de modelos de site specific.

75 Todavia, além de lúcidas, são bastante convincentes as discussões que Brissac (2002, p. 16-29) leva a cabo tematizando esses enquadramentos, para evidenciar o que há de realmente específico em seus projetos. Partindo de um conhecimento muito íntimo dos caminhos encetados pelas produções de arte que costumam ser designadas dentro da categoria de site specific, Brissac vai, passo a passo, contrastando as edições de Arte/Cidade de alguns desses modelos até encontrar o ponto exato em que essas edições podem ser definidas. Sigamos brevemente e com elipses os meandros do itinerário discursivo realizado pelo autor.

76 As práticas de sítio específico começaram a ser introduzidas no final dos anos 1960 com o propósito de incorporar o lugar no campo de percepção da obra artística contra a sua redução à imanência das relações internas. Entretanto, ocorreu que o sítio acabou por ser entendido em um sentido formal e estetizado do que decorreu muitos dos trabalhos serem reapropriados pelo circuito comercial, sendo reenviados aos museus (p. 18). Diante disso, artistas como Serra e Smithson (ver Brissac, 2010) redefiniram a noção de sítio, recorrendo "a escalas, métodos industriais de produção e processos de implantação que, em vez de simplesmente se adequar ao lugar, introduzem um olhar crítico sobre a situação urbana".

Quase vinte anos transcorridos, nos anos 1980, a busca por novos espaços para práticas artísticas já era norma a ponto de provocar ansiedade para o encontro de lugares não ocupados pela arte, o que levou a uma sobrevalorização de espaços até mesmo bizarros 
em detrimento da preocupação com a qualidade da obra. Com isso, mudaram os hábitos do receptor que passou a se deslocar do museu para deambular pelos itinerários urbanos, "numa retomada anacrônica do modelo do flâneur e sua fascinação com o estranhamento da cidade", até esta se ver, muitas vezes convertida em espetáculo, quando o mapa substitui a obra de arte e a cidade meramente substitui o museu. (ibid., p.18-19)

Dos anos 1980 para cá, a prática in situ foi se expandindo de tal forma até se tornar difusa, correndo o risco de ser "mais um modo disfarçado da publicidade e política corporativa". Em vez da especificidade do sítio, o que se desenvolve, muitas vezes, é o intercâmbio de lugares de criações que se movimentam de um lugar para o outro. Isso dá origem à figura do artista como interventor itinerante junto com a questão do mapeamento, em que trabalhos subsidiados "passam a tratar situações como sítios etnográficos. Usados para fazer não-lugares parecerem específicos novamente, restaurá-los como locais enraizados e não como espaços abstratos. Utilizados para reintroduzir valores como autenticidade e singularidade para uso dos patrocinadores" e tão ao gosto do turista cultural. $\mathrm{O}$ artista itinerante, por sua vez, pratica o nomadismo com sua presença performática, colaborativa e arregimentadora própria de um prestador de serviços que negocia, pesquisa, entrevista, coordena. Em alguns casos, quando se dá a busca de um maior engajamento no mundo externo e na vida cotidiana, a arte para lugar específico acaba por se converter em arte comunitária (ibid., p. 20).

79 A partir dos anos 1990, uma nova situação se delineou para colocar em questão o sítio específico como lugar alternativo para exposições: a complexidade crescente das megalópoles com seus espaços genéricos, amorfos, com áreas marcadas por desindustrialização, desertificação, reconstrução e reinserções altamente tensionadas de novas vias expressas de transporte e comunicações. Nas vastas manchas metropolitanas não há mais locais, mas territórios, com os quais a arte é chamada a contribuir "para redefinir o espaço urbano, ao criar novas tramas, com a arquitetura e o urbanismo ao redor, o espaço urbano" (ibid., p. 21).

80 A obra para sítio específico torna-se, assim, paradoxal uma vez que o local está em permanente mutação. As escolhas do sítio, portanto, não mais se fazem pela beleza, harmonia, exotismo, nostalgia ou outros atributos, mas por seu caráter entrópico. São "lugares dilacerados pela indústria, urbanização caótica e devastação da natureza" que não abrigam a circunscrição e o pertencimento. Ao contrário, remetem à experiência do abismo. Diante disso, longe de se ajustar a um contexto estático, "a obra passa a ser intervenção que desestrutura e redimensiona o lugar” (ibid., p. 23). Essa é a lição deixada por artistas como Robert Smithson, Gordon Matta-Clark e Dan Graham, principalmente. Como diria C. S. Peirce, uma lição que Brissac soube agarrar ao estender o arco de sua ação, com atenção no olhar e energia no braço. É por tudo isso que a aproximação dos projetos realizados por Brissac com arte para sítios específicos só pode ser feita com muito cuidado e precisão indagativa.

\section{Mídias locativas}

81 São bastante possíveis as analogias das artes para sítio específico com aquilo que ficou conhecido nos anos 2000 como projetos artísticos com mídias locativas. Locativo é um caso morfológico, em muitas línguas um prefixo, sufixo ou infixo, para indicar uma localização dentro de um lugar. São projetos que certamente brotaram, na época, sob o ímpeto dos dispositivos móveis geolocalizados e, muitas vezes, sensorializados que 
começaram a interfacear nossas vidas privadas e os espaços públicos que percorremos (ver Souza e Silva e Frith, 2012).

O termo foi cunhado em um workshop com esse nome que foi realizado pela RIXC, um centro eletrônico de arte e mídia na Letônia, em 2002. Desse evento originou-se um relatório que delineou o escopo para mídias locativas: "Os receptores baratos para satélites de posicionamento global deram aos amadores meios para produzir suas próprias informações cartográficas com precisão militar ... Ao contrário da World Wide Web, o foco aqui é espacialmente localizado, e centrado no usuário individual, uma cartografia colaborativa de espaço e mente, lugares e conexões entre eles". (Tuters e Varnelis, 2006)

Então, em 2004, durante o festival Transmediale, em Berlim, um projeto de mídia locativa intitulado .walk (ponto-walk) recebeu uma menção honrosa no prêmio de software do prestigiado festival. Desenvolvido por Social Fiction-Artes coletivas, situado em Utrecht, .walk combinava o código do computador com a exploração urbana "psicogeográfica". Tuters e Varnelis (ibid.) comentam que os participantes do .walk deixaram as portas da galeria para seguir um caminho gerado de forma aleatória através da cidade, "calculando" a cidade como se fosse um "computador peripatético". Do sucesso alcançado por esse projeto relativamente simples resultou um movimento maior que, até certo ponto, tomou conta da arte mídia, movimento que, propondo deixar para trás a arte da rede, pretendia, graças às mídias locativas, escapar dos limites da tela para entrar na cidade em geral. Contrapunha-se, portanto, à experiência dita descorporificada e baseada nas telas da net art, para reivindicar como seu território a inserção em um mundo além tanto das galerias quanto das telas dos computadores.

Foi enorme o número e a diversidade de tendências dos projetos de mídias locativas que surgiram e que foram cuidadosamente mapeados, entre outros, por Lenz (2004, ver também Santaella, 2010, p. 115-184). Entretanto, desde o início da segunda década do nosso século, arrefeceu o "hype" das artes das mídias locativas. Contudo, a despeito desse declínio específico, as tecnologias geoespaciais tomaram conta de nossas vidas e, mesmo que isso nos passe despercebido, condicionam muitos aspectos de nossa existência. Respondendo a essa "condição de ubiquidade" (Santaella, 2013), muitos artistas continuaram a usar a tecnologia locativa de maneira crítica, ao abrir sistemas fechados para tornar seus efeitos visíveis com vistas a reconfigurar nossas relações com eles. Uma síntese do estado da arte atualizado dos projetos artísticos de mídias locativas pode ser encontrado em Brucker-Cohen (2014).

Não se trata aqui de desenvolver uma discussão alongada sobre mídias locativas. A questão está sendo levantada, de um lado, devido aos seus parentescos mais próximos ou mais distantes com as artes para sítio específico. De outro lado, para verificar até que ponto -- ou até mesmo se porventura esse ponto existe -- é possível aproximar os projetos de Nelson Brissac das mídias locativas.

À primeira vista, essa tentativa de aproximação parece inoportuna, visto que os projetos de Brissac não tomam como foco dominante o papel mediador ou mesmo transformador da sociotécnica informatizada em si. Entretanto, para dar continuidade a essa discussão, antes de tudo, é preciso escapar de um sentido muito estreito de mídias locativas que limita o seu entendimento estritamente à exploração do potencial e/ou da crítica às mídias móveis geolocalizadas, ou seja, um entendimento que não vai além dos dados relativos ao nível das variáveis físicas de um território tais como condições de luz, 
temperatura, infraestrutura etc. Em um sentido mais amplo, sob essa superfície abrigamse os ideais que movem os projetos de mídias locativas e que se voltam para os fatores humanos de um território. Nesse nível superior de entendimento, os projetos de mídias locativas caracterizam-se por um feixe de fatores territoriais, tecnológicos, sociais, interativos e de interferência transformadora. Não é difícil perceber que se trata aí de um feixe que também se apresenta nos projetos de Brissac, especialmente em ZL Vórtice. A diferença, no entanto, encontra-se na dinâmica com que esse feixe é acionado e nos fatores que são enfatizados.

87 Embora atue no corpo a corpo com o território, mais ainda do que os projetos de mídias locativas, ZL Vórtice envolve tecnologia avançada como o modelo computacional de simulação hidrológica e hidráulica desenvolvido para a avaliação das diversas estratégias propostas de manejo de águas pluviais. Envolve também a mobilização e instrumentalização das comunidades, por meio de dispositivos de monitoramento, para acompanhar e melhor influir nas políticas públicas que afetam essas comunidades. Buscase inovação tecnológica no desenvolvimento de materiais e sistemas construtivos e informacionais pelos laboratórios da USP e da PUC-SP, que contam com a participação dos moradores locais. Os procedimentos são aprimorados junto aos moradores de modo a capacitá-los para implantar e conservar os dispositivos de infraestrutura e manejo de águas, visando à constituição de uma infraestrutura sustentável, adequada ao meio. Todavia, a grande diferença em relação aos projetos locativos não se encontra nesses aspectos, mas na concepção de território que, nos trabalhos de Brissac, se apresenta com um teor de originalidade radical.

88 Enquanto muitos dos projetos locativos ainda operam em função das especificidades estruturais e históricas dos lugares, desde Arte/Cidade Zona Leste, mais enfaticamente, os mapas dos territórios não são passíveis de desenhos. Mesmo que o território possa ser sensorializado por equipamentos avançados, não é desse território que se trata, pois os projetos lidam com escalas que não dizem mais respeito a lugares, "remetendo sempre a outros pontos da nebulosa urbana, ou seja, tratam das relações de distância e proximidade, de articulação e ruptura, que se podem estabelecer entre eles", para a constituição de tramas metropolitanas mais complexas, em escalas transurbanas, em redes formadas por prolongamentos e propagações (Brissac, 2002, p. 28).

\section{Artivismo e design de ativismo}

89 Quando são levados em conta os níveis de atuação de ZL Vórtice nas maneiras agudas com que busca interagir e interferir em vários pontos da realidade, melhor dizendo, nas suas práticas de mineração de realidade (reality mining), fica-se tentado a qualificar ZL Vórtice nos moldes daquilo que vem sendo chamado de "artivismo". Segundo Frostig (2011), este se define como o comprometimento e, mais do que isso, o engajamento da arte com a justiça social e processos transformativos sustentáveis.

90 Se considerarmos os vários níveis de atuação de ZL Vórtice, o título de artivismo parece lhe caber com justeza. No plano mais geral, da várzea, o projeto formula uma abordagem alternativa, viável e sustentável, para a implantação de infraestrutura e o manejo de águas em áreas ambientais. No nível local, busca-se desenvolver soluções de microdrenagem que possam ser produzidas e implantadas pelas próprias comunidades, possibilitando capacitação técnica e geração de renda aos moradores. Além disso, os programas de monitoramento e educação ambiental visam instrumentalizar as 
comunidades para melhor conhecer suas condições de vida e participar da formulação de políticas públicas. Todos esses níveis contam com a participação dos moradores em todas as suas fases, concepção, fabricação e instalação.

91 Entretanto, esses níveis são aqueles que mais aparecem porque são operacionais. Sob eles, existem camadas de investigação, de pesquisa que não são visíveis, mas pressupostas. Por isso mesmo, além de poder ser caracterizado como um projeto de artivismo, ZL Vortice estaria mais próximo de uma tendência recente nas artes sob o título de "design de ativismo" (activism design). Este é definido como representando o papel central do design para promover mudança social, para desenvolver a consciência sobre questões cruciais relativas à sustentabilidade, para questionar os constrangimentos culturais das mais variadas ordens. É certo que o design de ativismo compartilha algumas características com o ativismo político. Contudo, diferente deste, o design de ativismo não envolve boicotes, greves, protestos ou demonstrações. Como o próprio nome - "design" -- indica, a ênfase se coloca na pesquisa (Markussen, 2013). Ora, pesquisa e planejamento em vários níveis é justamente o que nunca faltou aos projetos de Arte/Cidade, tendo se intensificado em ZL Vórtice.

A complexidade e a escala das situações propostas nessa sequência de projetos nunca permitiram, sob pena de submissão acriticamente a elas, um processo de trabalho que não fosse fundado em projetos técnicos e apoios operacionais adequados. O que Brissac sempre tem procurado é evitar uma adequação intuitiva, em geral estetizante, aos locais. Por isso, as propostas desenvolvidas por Arte/Cidade nunca foram - e muito menos ZL Vórtice --, propriamente, projetos arquitetônicos e urbanísticos. São, isto sim, estratégias alternativas para a reestruturação global da cidade, em prol de políticas urbanas descentralizadas, baseadas na ativação desses espaços intersticiais, na dinamização sem concentração excludente, na heterogeneidade espacial e em diferenciais de velocidade.

Trata-se de uma cartografia urbana intensiva, que evidencie a complexidade e a dinâmica da área, a diversidade da ocupação e a potencialidade das operações em curso. Trabalhar na interseção desses diferentes vetores, nos intervalos surgidos no tecido fragmentado e nos fluxos descontínuos da megalópole. Provocar rearticulações entre as diversas situações, amplificando seu significado e impacto urbano, cultural e social e intensificando a percepção, por parte da população, destes processos. (Brissac, 2006, p. 88)

Ao contrário dos dispositivos expositivos convencionais, Arte/Cidade e muito mais $\mathrm{ZL}$ Vórtice assumem um alto grau de experimentação, lidando com fatores e variáveis que escapam à previsão e ao controle; componentes que dizem respeito ao jogo dos atores no espaço urbano, uma indeterminação que é própria da cidade em constante estado mutacional.

Pouco importa se Brissac se situa em proximidade ou distância, em atração ou retração das tendências artísticas que aqui foram comentadas. $O$ que, de fato, importa é que esse jogo de semelhanças e dessemelhanças traz munição para meu argumento de que Brissac pode até desempenhar com competência seus papeis de curador, designer, pesquisador, administrador etc., pois o que se perfila sobre tudo isso é o papel de um artista obstinadamente sustentando seu desejo, sem recuar diante dos entraves e das adversidades. A defesa que aqui proponho desse papel não tem por função lançar o artista no panteão dos fetiches culturais. Ao contrário, trata-se de reconhecer seu mérito como militante do admirável, esta que sempre foi e será a tarefa primordial da arte: materializar o admirável para tornar o mundo mais razoável. 


\section{BIBLIOGRAFIA}

\section{Referências}

AUGÉ, Marc, Não-lugares. Introdução a uma antropologia da supermodernidade, Trad. Maria Lucia Pereira, Campinas: Papirus, 1994.

AUGÉ, Marc, Por uma antropologia da mobilidade, Trads. Bruno César Cavalcanti e Rachel Rocha de A. Barros, São Paulo/Maceió: Unesp/UFAL, 2010.

BAUMAN, Zigmunt, Modernidade líquida, Trad. Plínio Dentzien, Rio de Janeiro, Zahar, 2001.

BRISSAC, Nelson, Arte/Cidade: um balanço, ARS (São Paulo), vol. 4, no.7, 2006, p. 85-89.

BRISSAC, Nelson, Paisagens críticas. Robert Smithson: Arte, ciência e industria, São Paulo: Educ/Senac/ Fapesp, 2010.

BRISSAC, Nelson, Arte/cidade: Zona Leste. Santiago de Compostela: Artedardo S.L., 2011.

BRISSAC, Nelson Brasmitte. In http://www.artecidade.org.br/site97_99/brasmitte/brasmitte02/ projeto_integra.html, s/d. Acesso: 30/08/2017.

BRISSAC, Nelson (org.), Arte/Cidade - Intervenções Urbanas,. São Paulo: Ed. SENAC, 2002.

BRUCKER-COHEN, Jonah. Locative media revisited. In http://rhizome.org/editorial/2014/ mar/26/locative-media-revisited/, 2014, Acesso: 10/09/2017.

FROSTIG, K. (2011), Arts Activism: Praxis in Social Justice, Critical Discourse, and Radical Modes of Engagement, Art Therapy: Journal of The American Art Therapy Association, 28(2), p. 50-56.

GAMA, Mara, Laboratório urbano, In Arte/Cidade - Intervenções urbanas, Nelson Brissac (org.), São Paulo: Ed. SENAC, 2002, p. 278-279.

GIUDICI, Bianca Gonçalves de Oliveira, Arte/Cidade. Vestígios da administração pública de um projeto de intervenção urbana, CELACC/ECA USP, 2014.

LENZ, Ronald. Locative, media. In

http://project.waag.org/parq/docs/LocativeMedia_ronald.pdf, 2004. Acesso: 15/08/2017.

MAMMI, Lorenzo, A cidade-caleidoscópio. Uma cidade morta nas entranhas da cidade atual, In Arte/Cidade - Intervenções urbanas, Nelson Brissac (org.). São Paulo: Ed. SENAC, 2002, p. 280-281.

MARKUSSEN, Thomas, The disruptive aesthetics of design activism: Enacting design between art and politics, Design Issues, volume 29, number 1, Winter 2013. Massachusetts Institute of Technology.

RANCIÈRE, Jacques, A partilha do sensível. Estética e política, Monica Costa Netto (trad.), São Paulo, Ed. 34, 2005.

RANCIÈRE, Jacques, Dissenso. In A crise da razão, Adauto Novaes (org., São Paulo: Companhia das Letras, 2000, p. 367-382.

SANTAELLA, Lucia, A ecologia pluralista da comunicação. São Paulo: Paulus, 2010. 
SANTAELLA, Lucia, Comunicação ubíqua. Repercussões na cultura e na educação. São Paulo: Paulus, 2013.

SECSP (Secretaria do Estado da Cultura de São Paulo),. Arte/cidade: Cidade sem janelas (catálogo). São Paulo: Editora Marca D’Água, 1994-1.

SECSP (Secretaria do Estado da Cultura de São Paulo), Arte/cidade: A cidade e seus fluxos (catálogo). São Paulo: Editora Marca D’Água, 1994-2.

SOUZA E SILVA, Adriana e FRITH, Jordan, Mobile interfaces in public spaces. Locational privacy, control, and urban sociability, New York and London, Routledge, 2012.

TUTERS, Marc e VARNELIS, Kazys, Beyond locative media. In

http://networkedpublics.org/locative_media/beyond_locative_media.html, 2006. Acesso: 15/09/2017.

\section{NOTAS}

1. https://www.sescsp.org.br/online/artigo/1171_ARTE+CIDADEZONA+LESTE

2. http://www.artecidade.org.br/site97_99/brasmitte/brasmitte02/projeto_integra.html

3. http://zlvortice.wordpress.com

\section{RESUMOS}

No campo complexo do atravessamento da arte, ciência e tecnologia por questões urgentes em estados permanentes de emergência no mundo contemporâneo, o objetivo deste artigo é colocar em discussão o atual projeto ZL Vórtice que se inscreve na sequência de quatro edições do projeto Arte/Cidade com início em 1994. Sob a tutela de Nelson Brissac, ZL Vórtice propõe interferir em zonas urbanas em condições extremas, colocando em rotação tendências estéticas e práticas artísticas tais como a partilha do sensível, artes de sítios específicos, mídias locativas, artivismo e design de ativismo.

In the complex field of the crossing of art, science and technology by urgent issues in permanent states of emergency in the contemporary world, the objective of this article is to put in discussion the current ZL Vortex project that follows the four editions of Arte / Cidade which began in 1994. Under the tutelage of Nelson Brissac, ZL Vortex proposes to interfere in urban areas in extreme conditions, putting in rotation aesthetic trends and artistic practices such as sensitive sharing, site specific, locative media, artivism and activism design.

\section{ÍNDICE}

Palavras-chave: Interferência urbana, megametrópoles, espaços intersticiais, arte/cidade.

Keywords: Urban interference, mega metropolis, interstitial spaces, art/city 


\section{AUTOR}

\section{LUCIA SANTAELLA}

Lucia Santaella é pesquisadora $1 \mathrm{~A}$ do CNPq, professora titular na pós-graduação em Comunicação e Semiótica e na pós-graduação em Tecnologias da Inteligência e Design Digital (PUCSP). Doutora em Teoria Literária pela PUCSP e Livre-docente em Ciências da Comunicação pela USP. Foi professora convidada em várias universidades no exterior. Já levou à defesa 248 mestres e doutores. Publicou 44 livros e organizou 16, além da publicação de perto de 400 artigos no Brasil e no exterior. Recebeu os prêmios Jabuti $(2002,2009,2011,2014)$, o prêmio Sergio Motta (2005) e o prêmio Luiz Beltrão (2010).lbraga[at]pucsp.br 